\title{
Effect of ozone gas processing on physical and chemical properties of wheat proteins
}

\author{
Mohammed Obadi, Ke-Xue Zhu, Wei Peng, Al-Farga Ammar and Hui-Ming \\ Zhou* \\ State key Laboratory of Food Science and Technology and School of Food Science and Technology, Jiangnan University, 1800 \\ Lihu Avenue, Wuxi 214122, PR China
}

*For correspondence: Email: obadialariki@gmail.com; Tel: +86 18861825344; Fax: +86 51085919389

\begin{abstract}
Purpose: To investigate the effects of ozone treatment on chemical and physical properties of wheat (Triticum aestivum L.) gluten, glutenin and gliadin.

Methods: Wheat proteins isolated from wheat flour were treated with ozone gas. The physical and chemical properties of gluten proteins were investigated after treatment with ozone gas, with $5 \mathrm{~g} / \mathrm{h}$ produced as a function of time $(0,30$, and $60 \mathrm{~min})$ in the study. To check whether the process of ozonation promoted changes in the quality of gluten proteins, sulfhydryl groups (SH), differential scanning calorimetry (DSC), secondary structure, SDS-PAGE, and rheology analyses were performed. Results: Sulfhydryl group contents of wheat proteins ranged from 1.1 to $7.12 \mu \mathrm{mol} / \mathrm{g}$. Sulfhydryl group content for all ozonated proteins was significantly lower than that of the control samples. Gluten proteins showed reduced SDS-PAGE band intensities of both high (HMW) gluten and glutenin subunits with increasing ozone gas treatment. The denaturation temperatures (Td) of ozonated gluten proteins were higher $\left(99.80-106.79^{\circ} \mathrm{C}\right)$ and the enthalpies of the ozonated gluten proteins were lower than those of the control samples. The storage moduli (G') and loss moduli (G") of gluten and glutenin tended to increase from 7.84 to $10.20 \mathrm{KPa}$ and 43.19 to $48.28 \mathrm{KPa}$, and from 3.33 to $4.06 \mathrm{KPa}$ and 20.74 to $22.56 \mathrm{KPa}$, respectively, as ozone exposure increased from 0 to $30 \mathrm{~min}$.

Conclusion: Ozone gas can oxidize wheat proteins. Exposing wheat proteins to ozone gas for an extended time $(60 \mathrm{~min})$ deteriorated wheat protein quality.
\end{abstract}

Keywords: Ozone treatment, Gluten proteins, Chemical changes, Rheological studies, CD spectroscopy, Thermal properties.

Tropical Journal of Pharmaceutical Research is indexed by Science Citation Index (SciSearch), Scopus, International Pharmaceutical Abstract, Chemical Abstracts, Embase, Index Copernicus, EBSCO, African Index Medicus, JournalSeek, Journal Citation Reports/Science Edition, Directory of Open Access Journals (DOAJ), African Journal Online, Bioline International, Open-J-Gate and Pharmacy Abstracts

\section{INTRODUCTION}

Wheat (Triticum aestivum L.) gluten is very important for bread making. Grain proteins are classically divided into two fractions. Gliadins are present as monomers that either lack disulphide bonds or contain only intra-chain bonds; they provide cohesion and are responsible for the extensibility of gluten. Glutenins are polymeric, with high molecular weight, and they form complex polymers stabilized by inter-chain disulphide bonds. Glutenins contribute to the elasticity of gluten [1]. Ozone is one of nature's most powerful oxidants. It serves as a disinfectant in water treatments, destroys storage pests, and degrades mycotoxins to treat foods by sterilization [2]. Ozone has been used in the food processing industry, and is affirmed as generally recognized and safe (GRAS) [3]. The literature has demonstrated the efficacy of ozone for preservation of food grains. Tiwari et al [4] and 
Naito et al [5] demonstrated that ozone-treated grains at high concentrations (> 50 ppm) caused oxidative damage in cereal grain flours. Oxidation of sulfhydryl groups to disulfide bonds increases unextractable polymeric protein content [6]. There are growing areas of applications of ozone in the industry, but a limited amount of research has focused on using ozone as an oxidant of wheat proteins. The extent to which oxidation affects the physical and chemical properties of wheat proteins is unknown. In this study, the physiochemical properties of proteins (i.e., gluten, glutenin, and gliadin) isolated from non-ozone-treated flour were examined by studying chemical characteristics using SDSPAGE, free SH groups, differential scanning calorimetry (DSC) parameters, secondary structure, and rheological measurements.

\section{EXPERIMENTAL}

\section{Preparation of gluten, glutenin, and gliadin}

Wheat flower with medium protein content was obtained from the China Oil and Foodstuffs Corporation Co., Ltd. The protein content was $10.20 \%$ on a dry basis. This flour was not bleached and had no added ingredients. A $300 \mathrm{~g}$ flour sample was mixed with $\mathrm{NaCl}$ solution (0.4 $\mathrm{M}, 160 \mathrm{~mL}$ ) in a Farinograph. Then, after several minutes of resting time, the dough was washed manually with an $\mathrm{NaCl}$ solution $(0.4 \mathrm{M}, 3 \mathrm{~L})$ until a cohesive mass (gluten) was obtained. The crude gluten was washed with distilled water to remove $\mathrm{NaCl}$, followed by centrifugation at 5000 rpm for $10 \mathrm{~min}$. Gluten $(20 \mathrm{~g})$ was shaken with dichloromethane $(300 \mathrm{~mL})$ for $1 \mathrm{~h}$ at room temperature to separate the glutenin and gliadin, filtered through filter paper, and filtered with Whatman filters. The procedures described above were repeated three times. Then, the gluten was dried at room temperature. Gliadin was extracted from $20 \mathrm{~g}$ of a $60 \%$ gluten sample for $30 \mathrm{~min}$, vortexed for $1 \mathrm{~min}$ every $10 \mathrm{~min}$, and centrifuged for $10 \mathrm{~min}$ at $3000 \mathrm{rpm}$. Extraction was performed three times. The supernatants were pooled, and ethanol was removed using a rotary evaporator at $30{ }^{\circ} \mathrm{C}$. Prior to the second and third extraction steps, the cohesive glutenin was mechanically disrupted with a spatula. The extraction was performed at $20{ }^{\circ} \mathrm{C}$ for $3 \mathrm{~h}$, with centrifuging (4000 rpm, at $4{ }^{\circ} \mathrm{C}$ for $10 \mathrm{~min}$ ) after each extraction. Following ethanol extraction, the gliadin and glutenin sediments were freeze-dried.

\section{Ozone treatment}

Proteins (gluten, glutenin, and gliadin) isolated from non-ozone-treated flour were treated with ozone gas using an ozone generator (model OJ-
8003k-A, Guangzhou, China) with production of $5 \mathrm{~g} / \mathrm{h}$. After freeze-drying the gluten, the glutenin and gliadin samples were placed in a reaction vessel (rotating vessel designed for an evaporator) connected to the ozone generator. The samples were exposed to ozone gas for 0 , 30 , and $60 \mathrm{~min}$. Air flow was set at $5 \mathrm{~L} / \mathrm{min}$. All samples were prepared in triplicate.

\section{SDS-PAGE (sodium dodecyl sulfate- polyacrylamide gel electrophoresis) analysis}

Sodium dodecyl sulfate-polyacrylamide gel electrophoresis (SDS-PAGE) analysis was performed on $10 \%$ polyacrylamide gel. Proteins were separated in a 1-mm-thick preparative gel consisting of $4 \%$ stacking gel and $12 \%$ resolving gel. The gluten and glutenin samples (5 $\mathrm{mg}$ ) were extracted with $1 \mathrm{~mL}$ of a non-reduced sample buffer solution containing $0.125 \mathrm{M}$ Tris$\mathrm{HCl}, 2 \%$ (w/v) SDS, $10 \%$ (v/v) glycerol, and $0.01 \% \mathrm{w} / \mathrm{v}$ bromophenol blue at a $\mathrm{pH}$ of 6.8 .

The protein-buffer mixtures were vortexed for 2 min and allowed to stand at room temperature for $2 \mathrm{~h}$. Then, they were centrifuged at 35,714 rpm for $20 \mathrm{~min}$ at $4{ }^{\circ} \mathrm{C}$, and the supernatant was heated for $3 \mathrm{~min}$ at $90{ }^{\circ} \mathrm{C}$ in a boiling water bath. After cooling to room temperature, the samples $(50 \mu \mathrm{L})$ were loaded onto the gels. For reduced proteins, the sample buffer contained $5 \%(\mathrm{v} / \mathrm{v})$ $\beta$-mercaptoethanol. Electrophoresis was conducted at room temperature, with constant voltage at $100 \mathrm{~V}$.

\section{Determination of free SH groups}

To determine the concentration of free sulfhydryl (SH) groups in gluten proteins, the following solvents were used: Tris-glycine-EDTA (TGEEDTA; $10.4 \mathrm{~g}$ of Tris, $6.9 \mathrm{~g}$ of glycine, and $1.2 \mathrm{~g}$ of EDTA per liter, $\mathrm{pH}=8.0$, denoted as TGE buffer); $2.5 \%$ SDS in TGE (SDS-TGE); and Ellman's reagent (5,50-dithiobise2-nitrobenzoic acid, DTNB) in TGE (4 mg/mL). The $40 \mathrm{mg}$ of samples were incubated with $4 \mathrm{~mL}$ of SDS-TGE for $30 \mathrm{~min}$ and vortexed every $10 \mathrm{~min}$. Then, 0.04 $\mathrm{mL}$ of Ellman's reagent was added and mixed in a $25{ }^{\circ} \mathrm{C}$ water bath for $30 \mathrm{~min}$ to prevent a light reaction.

Absorbance values were converted to concentrations of free $\mathrm{SH}$, using a calibration curve with reduced glutathione. The solution was then subjected to centrifugation at $5000 \mathrm{rpm}$ for $15 \mathrm{~min}$, and the absorbance of the supernatant was measured at $412 \mathrm{~nm}$ against the blank sample, which lacked Ellman's reagent and a sample. 


\section{Differential scanning calorimetry (DSC)}

Differential scanning calorimetry (DSC) analysis was conducted using a TA Q100-DSC thermal analyzer (TA Instruments, Newcastle, DE, USA) following [7]. Approximately $2.0-3.0 \mathrm{mg}$ of protein samples were weighed in aluminum pans, hermetically sealed, and heated in the DSC from 20 to $150{ }^{\circ} \mathrm{C}$ at $5{ }^{\circ} \mathrm{C} / \mathrm{min}$ using $\mathrm{N}$ gas at a flow rate of $80 \mathrm{~mL} / \mathrm{min}$. An empty pan was used as a reference. The denaturation peak temperature $(\mathrm{Td})$ and enthalpy $(\Delta \mathrm{H})$ were obtained, and the half-peak height and width of endothermic peaks were obtained from thermograms using Universal Analysis 2000 (version 4.1D software; TA Instruments Waters, LLC, Newcastle, DE, USA).

\section{Circular dichroism (CD) spectroscopy}

A $0.1-\mathrm{mg} / \mathrm{mL}$ sample of a gliadin fraction solution in $50 \%(\mathrm{v} / \mathrm{v})$ ethanol was analyzed using a CD spectrophotometer (Biologic Science Instruments, Grenoble, France). The light path was adjusted $(190-250 \mathrm{~nm})$ using a $0.1-\mathrm{cm}$ quartz cuvette [8].

\section{Fourier transforms infrared (FTIR) spectroscopy}

Fourier transforms infrared (FTIR) spectra were recorded on an FTIR spectrophotometer (NEXUS, Thermo., US) with single-reflection diamond attenuated total reflection (ATR) and mercury-cadmium-telluride (MCT) detectors. Spectra of an empty cell were used as a background, and cells were recorded for 64 scans at $4-\mathrm{cm}^{-1}$ resolution. Hydrated samples were placed on the ATR crystal, and the spectra were recorded under the same conditions as the background. Two sub-samples were used for each determination. Experiments were conducted at room temperature using OMNIC software (version 6.1a, Thermo Nicolet Corp.) to evaluate secondary structural changes in the protein [9].

\section{Rheological studies}

Dynamic rheological measurements were recorded at $25{ }^{\circ} \mathrm{C}$ with a Rheometer AR 1000 (TA Instrument, Newcastle, DE) using parallelplate geometry (40-mm diameter, $1-\mathrm{mm}$ gap). Protein samples were sheared at $0.2 \%$ strain through a frequency sweep from 0.1 to $10 \mathrm{~Hz}$ and at a constant temperature of $25{ }^{\circ} \mathrm{C}$. Hydrated gluten and glutenin samples were preshaped to disks $(25 \mathrm{~mm}$ diameter, $5 \mathrm{~mm}$ thickness), relaxed for $30 \mathrm{~min}$, and fixed to the parallel plates of the stress rheometer coated with thin films of cyanoacrylate. The edges of the samples were covered with paraffin oil. The 3$\mathrm{mm}$ gap was adjusted within $5 \mathrm{~min}$, followed by a final relaxation of $10 \mathrm{~min}$ before measurements were recorded.

\section{Statistical analysis}

Each experiment was performed in triplicate, and the means and standard deviations (SDs) were calculated. SPSS 16.0 for Windows software was used for statistical analysis. Analysis of variance (ANOVA) was followed by Duncan's multiple comparison test to assess differences. The significance level was defined as $p<0.05$.

\section{RESULTS}

\section{Protein profile}

To better understand this phenomenon, both reduced (Fig. 1A) and non-reduced (Fig. 1B) SDS-PAGE were performed to characterize the changes in gluten and glutenin proteins treated with ozone gas. Ozone gas had no effect on these proteins. The protein-reducing patterns are shown in Fig. 1B. There were no major differences in most of the visible bands among all samples.

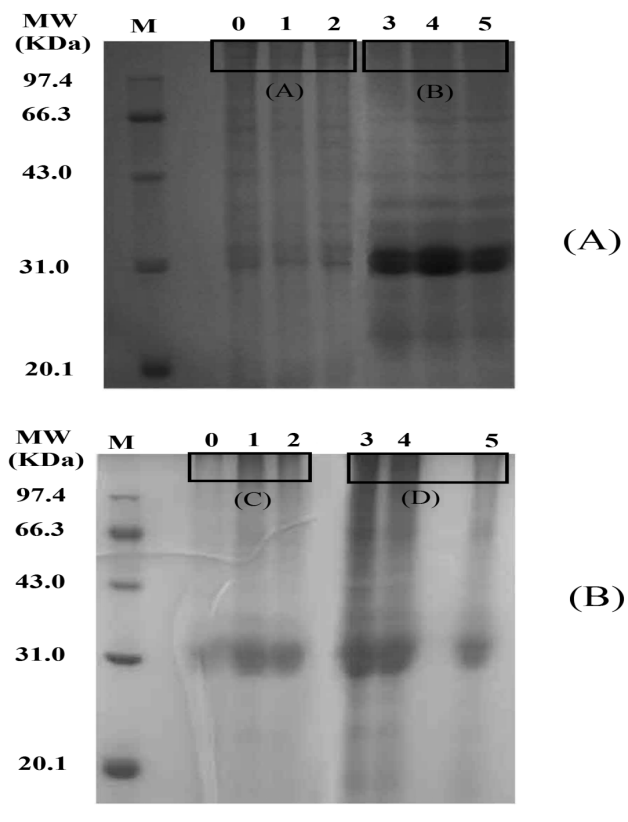

Figure 1: SDS-PAGE analysis of protein patterns in wheat gluten and glutenin, with and without ozone treatment. (A): The reduced patterns; (B): The nonreduced patterns; Lanes: glutenin exposed to ozone gas for $0 \mathrm{~min}(0), 30 \mathrm{~min} \mathrm{(1),} \mathrm{and} 60 \mathrm{~min}$ (2); gluten exposed to ozone gas for $0 \mathrm{~min}(3), 30 \mathrm{~min}$ (4), and 60 min (5); M, molecular weight standard 


\section{Ozone gas effect on SH groups}

Ozone gas has been used to promote the oxidation of sulfhydryl groups, which results in the formation of disulfide bonds among glutenin molecules [10]. Gliadins are monomers with intra-chain disulfide bonds, whereas glutenin polymers have both intra and inter-chain disulfide bonds. Disulfide bonds are known to play an important role in maintaining the gluten network structure. Gluten depolymerized by disulfide bond breakage was used to increase the free $\mathrm{SH}$ content [11]. Free $\mathrm{SH}$ group exposure was monitored as a function of treatment time. The free $\mathrm{SH}$ group content in wheat gluten, glutenin, and gliadin decreased significantly as ozone treatment time increased (Fig. 2). This was likely due to the disulfide bonds formed in these proteins in response to ozone treatment. The $\mathrm{SH}$ content in gluten was reduced from 7.12 to 4.88 $\mu \mathrm{mol} / \mathrm{g}$ with increased ozone gas treatment (Fig. 2). The SH content of glutenin was reduced from 4.20 to $2.50 \mu \mathrm{mol} / \mathrm{g}$, and that of gliadin from 2.04 to $1.10 \mu \mathrm{mol} / \mathrm{g}$ with increasing ozone gas treatment.

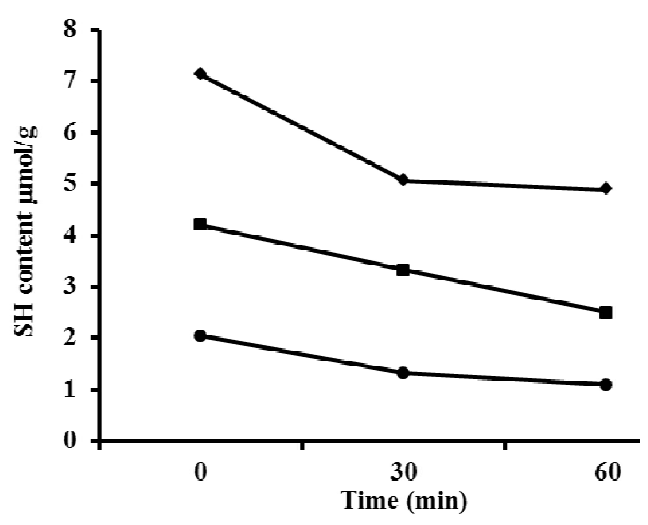

Figure 2: Effect of ozone treatment on the SH content of gluten proteins. Gluten - $\downarrow-$, Glutenin - - -, Gliadin - - The data are mean values computed over three replicates

\section{Thermal properties}

To investigate the effect of ozone gas on thermal properties of gluten proteins, samples were thermally scanned in a DSC. The denaturation temperature and enthalpy $\Delta \mathrm{H}$ are the main parameters of the DSC profile. They occur during the baking process and 'setting' of the gluten network, significantly affecting the characteristics of the baked products [12]. In the present study, the results showed a slight increase in the denaturation transition temperature $\left(T_{d}\right)$ of gliadin compared to samples not treated with ozone (Table 1).

\section{Secondary structure}

Far-UV circular dichroism (CD) spectroscopy was used to study the conformation of gliadin exposed to ozone gas [13]. FTIR spectroscopy is a useful tool to characterize protein secondary structures, with precision between the purely predictive and molecular coordinate approaches [14]. FTIR spectroscopy was used to determine secondary structures of gluten and glutenin viscoelastic bodies. The amide I band (1600$1700 \mathrm{~cm}^{-1}$ ) in FTIR spectra was mainly correlated with the secondary structure. We investigated how ozone treatment changed the structure of wheat gluten. As shown in Figure 3, the gluten and glutenin secondary structures in the control sample were $30.1 \%$ and $28.3 \%$ of the a-helix, $10.2 \%$ and $25.5 \%$ of the $\beta$-sheet, and $22.4 \%$ and $18.7 \%$ of the random coil for gluten and glutenin, respectively. After ozone exposure for $60 \mathrm{~min}, 33.6 \%$ and $35.6 \%$ of the a-helix, $11.8 \%$ and $28.09 \%$ of the $\beta$-sheet, and $21.1 \%$ and 18.3 $\%$ of the random coil were observed in gluten and glutenin, respectively.

Table 1: Differential scanning calorimetry data for proteins subjected to ozone treatment

\begin{tabular}{llcc}
\hline Protein & Sample & Enthalpy $(\Delta \mathbf{H}, \mathbf{J} / \mathbf{g})$ & Denaturation $\left(\mathbf{T}_{\mathbf{d}},{ }^{\circ} \mathbf{C}\right)$ \\
\hline \multirow{3}{*}{ Gluten } & Control & $29.39 \pm 0.08^{\mathrm{a}}$ & $100.00 \pm 0.001^{\mathrm{c}}$ \\
& $30 \mathrm{~min}$ & $23.25 \pm 1.02^{\mathrm{b}}$ & $103.10 \pm 0.21^{\mathrm{b}}$ \\
& $60 \mathrm{~min}$ & $16.80 \pm 0.05^{\mathrm{c}}$ & $105.68 \pm 0.09^{\mathrm{a}}$ \\
\hline \multirow{3}{*}{ Glutenin } & Control & $30.22 \pm 1.02^{\mathrm{a}}$ & $98.79 \pm 0.92^{\mathrm{c}}$ \\
& $30 \mathrm{~min}$ & $24.07 \pm 1.80^{\mathrm{b}}$ & $102.38 \pm 1.60^{\mathrm{b}}$ \\
& $60 \mathrm{~min}$ & $13.08 \pm 1.12^{\mathrm{c}}$ & $106.79 \pm 1.07^{\mathrm{a}}$ \\
\hline \multirow{3}{*}{ Gliadin } & Control & $17.49 \pm 0.50^{\mathrm{a}}$ & $97.12 \pm 0.60^{\mathrm{c}}$ \\
& $30 \mathrm{~min}$ & $13.48 \pm 0.42^{\mathrm{b}}$ & $99.80 \pm 1.00^{\mathrm{b}}$ \\
& $60 \mathrm{~min}$ & $8.64 \pm 0.57^{\mathrm{c}}$ & $101.00 \pm 0.98^{\mathrm{a}}$ \\
\hline
\end{tabular}



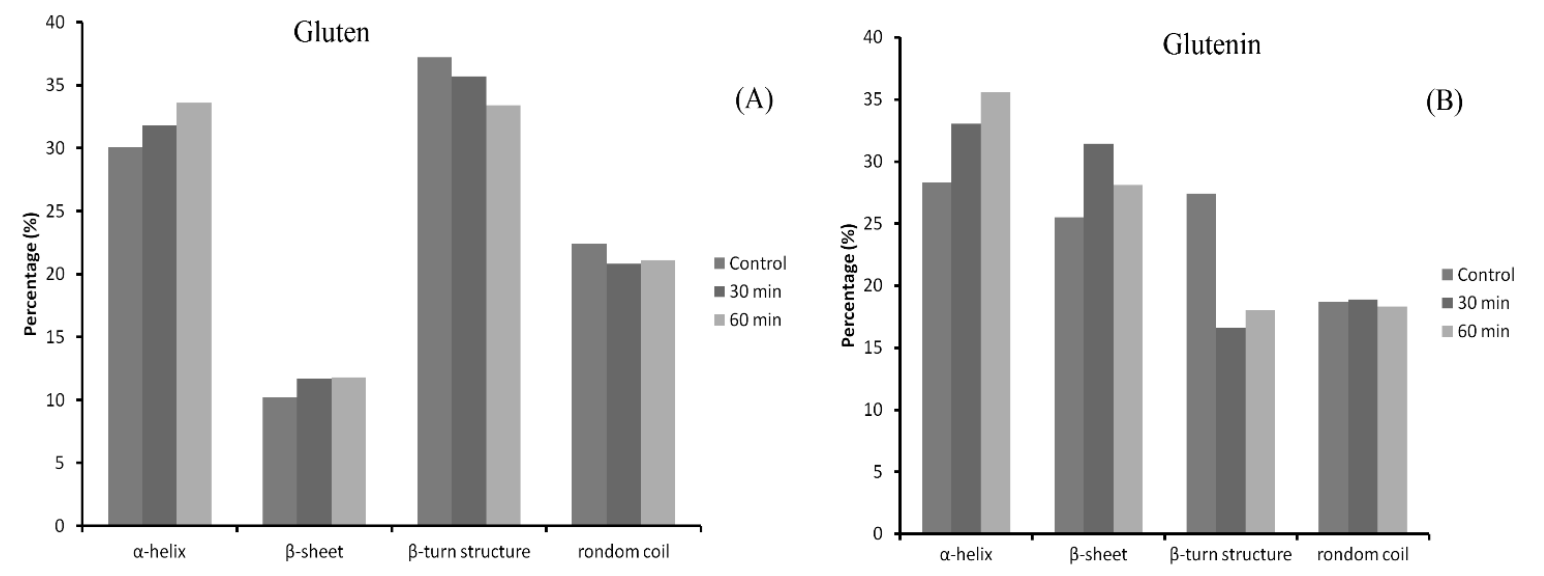

Gliadin

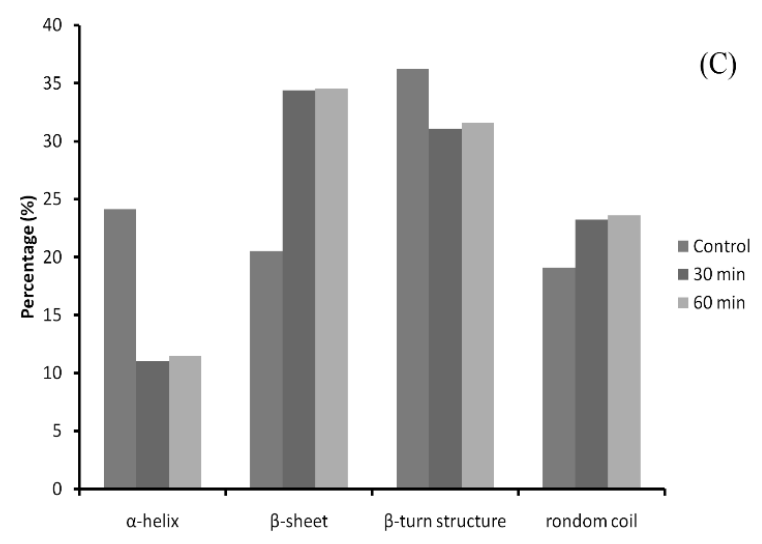

Figure 3: Secondary structural changes in gluten proteins treated for different times with ozone gas

Table 2: Effect of ozone gas treatment on dynamic viscosities of gluten, glutenin, and gliadin

\begin{tabular}{|c|c|c|c|c|}
\hline $\begin{array}{c}\text { Ozone } \\
\text { treatment } \\
\text { duration }(\mathrm{min})\end{array}$ & Parameter & Gluten & Glutenin & Gliadin \\
\hline $0 \mathrm{~min}$ & $\begin{array}{c}\mathrm{G}^{\prime}(\mathrm{KPa}) \\
\mathrm{G}^{\prime \prime}(\mathrm{KPa}) \\
\text { Tan } \delta\end{array}$ & $\begin{array}{c}7.84 \pm 0.67^{\mathrm{b}} \\
3.32 \pm 0.002^{\mathrm{b}} \\
0.42 \pm 0.06^{\mathrm{b}}\end{array}$ & $\begin{array}{c}43.19 \pm 1.007^{\mathrm{D}} \\
20.74 \pm 0.00^{\mathrm{b}} \\
0.13 \pm 0.001^{\mathrm{c}}\end{array}$ & $\begin{array}{c}0.75 \pm 0.099^{b} \\
0.73 \pm 0.02^{b} \\
0.44 \pm 0.07^{c}\end{array}$ \\
\hline $30 \mathrm{~min}$ & $\begin{array}{c}\mathrm{G}^{\prime}(\mathrm{KPa}) \\
\text { G” (KPa) } \\
\text { Tan } \delta\end{array}$ & $\begin{array}{l}10.20 \pm 0.33^{a} \\
4.06 \pm 0.001^{a} \\
0.42 \pm 0.029^{b}\end{array}$ & $\begin{array}{c}48.24 \pm 0.09^{\mathrm{a}} \\
22.56 \pm 0.003^{\mathrm{a}} \\
0.16 \pm 0.041^{\mathrm{b}}\end{array}$ & $\begin{array}{c}1.21 \pm 0.02^{\mathrm{a}} \\
1.05 \pm 0.019^{\mathrm{a}} \\
0.68 \pm 0.009^{\mathrm{b}}\end{array}$ \\
\hline $60 \mathrm{~min}$ & $\begin{array}{c}\mathrm{G}^{\prime}(\mathrm{KPa}) \\
\text { G" (KPa) } \\
\text { Tan } \delta\end{array}$ & $\begin{array}{l}5.54 \pm 0.04^{c} \\
2.40 \pm 0.07^{c} \\
0.45 \pm 0.008^{a}\end{array}$ & $\begin{array}{l}38.77 \pm 0.04^{\mathrm{c}} \\
12.13 \pm 0.08^{\mathrm{c}} \\
0.17 \pm 0.005^{\mathrm{a}}\end{array}$ & $\begin{array}{l}1.21 \pm 0.014^{a} \\
0.97 \pm 0.006^{a} \\
0.83 \pm 0.006^{a}\end{array}$ \\
\hline
\end{tabular}

\section{Rheological properties}

Gluten plays a major role in the rheological properties of flour dough that are important for the quality of bakery products. The averages of three measurements of elastic modulus ' $G^{\prime}$, viscous modulus $G$ ", and Tan $\delta$ for the gluten, glutenin, and gliadin in samples that had been ozonated for different times are shown in Table 2. Gluten and glutenin had predominately viscoelastic solid behavior, whereas gliadins mainly conferred viscous flow, indicating dominance of the elastic characteristic [15].
Elastic modulus G' and viscous modulus G" of gluten and glutenin in samples exposed to ozone for varying times are presented in Table 2 . The gluten and glutenin of protein samples exposed to ozone for $30 \mathrm{~min}$ exhibited increased modulus $G^{\prime}$ and viscous modulus $G^{\prime \prime}$ compared to the control.

\section{DISCUSSION}

These SDS-PAGE results are in agreement with the findings of $\mathrm{Li}$ et al [16], which showed that ozone treatment had no effect on the band 
intensities in reduced SDS-PAGE patterns. In contrast to the proteins, significant effects on gluten- and glutenin-ozonated samples were observed for the non-reduced SDS-PAGE patterns. The effect was particularly noticeable in terms of the intensity of bands within the range of $31-45 \mathrm{kDa}$ in ozone-treated glutenin. In addition, an increase in the intensity of bands was observed in glutenin. A very remarkable reduction in band intensity was observed in gluten samples exposed to ozone for $60 \mathrm{~min}$. These results indicate that protein treated with ozone for extended periods might cause scission of the disulfide bond (S-S bonds); this would help to break down the protein structure, and the labile peptide and amide bonds would be ruptured. Oxidation from ozone treatment of gluten and glutenin (60 min) caused partial depolymerization of high-molecular-weight proteins and increased content of low-molecularweight protein polymers.

The increase in disulfide bonds improves the gluten matrix by sulphydryl group oxidization, thus increasing the cross-linking of protein polymers. Glutenin subunits were polymerized with inorganic oxidization using $\mathrm{K}$ iodation, $\mathrm{K}$ bromation, and hydrogen peroxide, as described by Veraverbeke et al $[17,18]$, and molecular oxygen [19]. This polymerization was due to the oxidation of $\mathrm{SH}$ groups. Cataldo [20] reported that ozone oxidizes cysteine in protein to form cystine disulfide bonds. The results from our study were similar to those reported by Chittrakorn [10], who also found that $\mathrm{SH}$ groups were oxidized during chlorine treatment. Ozone treatment oxidized sulfhydryl groups to disulfide bonds, which could explain the increased dough strength [6].

These values are similar to those reported by Sinha et al [21], who stated that chlorination caused a slight increase in denaturation of gliadin. Myers [22] reported that large increases in denaturation (Td) values are expected for proteins with a high proportion of hydrophobic residues involved in the denaturation mechanism. In the present study, the $T_{d}$ values of ozone-treated and non-ozone-treated samples were not significantly different. However, ozonetreated samples had slightly higher $T_{d}$ values, indicating an increase in the hydrophobicity of ozonated samples. Falcao-Rodrigues et al [16] proposed that the denaturation of gluten proteins is accompanied by decreased solubility, and proceeds to a point where the gas vesicle walls are fixed and expansion ends. Thus, the higher $T_{d}$ of gliadins treated with ozone would result in large gas cells and higher loaf volume in bread. The results from the DSC analysis showed that ozone treatment decreased the enthalpies $\Delta \mathrm{H}$ of gluten proteins. The reduction in enthalpies $\Delta \mathrm{H}$ of ozone-treated proteins might be due to ozone gas, which caused unfolding of gluten proteins, disrupting the ordered structure during treatment. Sinha et al [21] also found a decrease in the enthalpy $\Delta \mathrm{H}$ value in of chlorinated gliadin samples. Deterioration of gluten proteins caused disruption in the ordered structure, which could weaken baked goods.

These results suggest that $\beta$-sheet and $\alpha$-helix are sensitive to the action of ozone. Changes in the content of $\beta$-sheet and random coil structures of proteins exposed to ozone treatment affect intermolecular hydrogen bonding of the $\beta$-sheets. Misra NN et al and Safonova et al [23,24] reported that ozone gas affected the secondary structure of wheat flour proteins based on FTIR spectroscopy results. The CD spectra calculation indicated a significant decrease (approximately $12 \%)$ in the a-helix for gliadin samples in response to increased ozone gas treatments. Both the $\beta$-sheet and random coil increased by nearly 14 and $4 \%$, respectively with increased ozone gas treatments. Enhancement of the $\alpha-$ helix structure had detrimental effects on the $\beta$ sheet and random coil structures. The effects on the secondary structure caused some conformational changes in ozone-treated wheat gluten. New intermolecular cross-links would appear to cause joining within two molecular proteins and changes in the secondary structures.

After $30 \mathrm{~min}$ of exposure to ozone, gluten and glutenin of the protein samples displayed decreased elastic modulus G' compared with control samples. This decrease might be attributed to the reduced functional properties of protein due to oxidation by ozone exposure. This was confirmed by our SDS-PAGE analysis of gluten proteins, where overexposure of gluten proteins to ozone caused partial depolymerization of high-molecular-weight proteins and increased the content of lowmolecular-weight protein polymers.

Ozone may have influenced more protein molecules with increased exposure to gas ozonation, causing an extensive change in the protein structure, which appeared as differences in rheological properties. Tan $\delta$ is generally an indicator of protein quality [25]. Tan $\delta$ gives a measure of the viscous and elastic response of the material being tested. Tan $\delta$ values of ozonated gluten and glutenin increased compared to the control. However, further treatment of gluten and glutenin with ozone gas (60 min) increased tan $\delta$ (Table 2). These 
changes might be due to the deteriorating protein quality. This was probably attributable to the depolymerization of GMP in gluten and glutenin due to overexposure of proteins to ozone. Over oxidation of proteins would make the dough too weak and susceptible to expanding during baking. It is also hypothesized that excess formation of disulfide bonds over longer periods of time, with the accompanying loss of sulfhydryl groups, might hinder disulfide bond interchange, leading to more rapid breakdown of dough. An earlier study suggested that glutenin polymerization leads to a significant increase in the elastic modulus of the network [26]. A significant correlation exists between viscoelastic properties in the dough and the amount of the glutenin macro polymer (GMP) [27]. Ozone could be used to improve protein quality and change rheological properties to make the dough more elastic.

\section{CONCLUSION}

Ozone gas treatment has been applied to gluten, glutenin, and gliadin samples to estimate the nature and extent of changes in gluten protein properties. Overall, the findings revealed that exposing gluten proteins to ozone gas for a short period of time (30 min) enhanced its physical and chemical properties (SDS-PAGE, SH, DSC, secondary structure, and rheology properties) than longer term (60 $\mathrm{min}$ ) exposure to ozone gas.

\section{DECLARATIONS}

\section{Acknowledgement}

The authors would like to acknowledge Priority Academic Program Development of Jiangsu, Higher Education Institutions, Wuxi City, Jiangsu Province, People's Republic of China.

\section{Conflict of Interest}

No conflict of interest associated with this work.

\section{Contribution of Authors}

The authors declare that this work was done by the authors named in this article and all liabilities pertaining to claims relating to the content of this article will be borne by them.

\section{REFERENCES}

1. Shewry PR, Lookhart GL. Wheat gluten protein analysis. American Association of Cereal Chemists. 2003.
2. Cullen PJ, Tiwari BK, O'Donnell CP, Muthukumarappan $K$. Modelling approaches to ozone processing of liquid foods. Trends Food Sci Technol. 2009; 20(3-4):125136.

3. Graham DM. Use of ozone for food processing. Food Technol. 1997; 51: 121-137.

4. Tiwari B K, Brennan CS, Curran T, Gallagher E, Cullen $P J$, O'Donnell CP. Application of ozone in grain processing. J. Cereal Sci. 2010; 51(3): 248-255.

5. Naito S, Shiga I. Studies on utilization of ozone in feed preservation .9. Effect of ozone treatment on elongation of hypocotyl and microbial counts of bean sprouts. Journal of the Japanese Society for Food Science and Technology-Nippon Shokuhin Kagaku Kogaku Kaishi. 1989; 36 (3): 181-188.

6. Sandhu HPS, Manthey FA, Simsek S. Quality of bread made from ozonated wheat (Triticum aestivum L.) flour. J Sci Food Agr. 2011; 91(9): 1576-1584.

7. Meng, GT Ching, KM Ma, CY Thermal aggregation of globulin from an indigenous Chinese legume (Phaseolus angularis) red bean. Food Chem. 2002; 79: 93-103.

8. Kieffer $R$, Schurer $F$, Kohler $P$, Wieser $H$. Effect of hydrostatic pressure and temperature on the chemical and functional properties of wheat gluten: studies on gluten, gliadin and glutenin. J. Cereal Sci. 2007; 45(3): 285-292.

9. Almutawah A, Barker SA, Belton PS. Hydration of gluten: a dielectric, calorimetric, and Fourier transform infrared study. Biomacromolecules. 2007; 8(5): 1601-1606.

10. Chittrakorn, S. Use of Ozone as an Alternative to Chlorine for Treatment of Soft Wheat Flours. Ph.D. Thesis. Kansas State University. 2008.

11. Wrigley CW. Biopolymers Giant proteins with flour power. Nature. 1996; 381(6585): 738-739.

12. Falcaò-Rodrigues MM, Moldaò-Martins M, Beiraò-daCosta ML. Thermal properties of gluten proteins of two soft wheat varieties. Food Chem. 2005; 93: 459-465.

13. Provencher SW, Gloeckner J. Estimation of globular protein secondary structure from circular dichroism. Biochemistry. 1981; 20(1): 33-37.

14. Jackson M, Mantsch HH. The use and misuse of FTIR spectroscopy in the determination of protein structure. Crit. Rev. Biochem. Mol. Biol. 1995;30(2): 95-120.

15. Singh S, Singh N. Relationship of polymeric proteins and empirical dough rheology with dynamic rheology of dough and gluten from different wheat varieties. Food Hydrocoll. 2013; 33(2): 342-348.

16. Li M, Zhu KX, Wang BW, Guo XN, Peng W, Zhou HM. Evaluation the quality characteristics of wheat flour and shelf-life of fresh noodles as affected by ozone treatment. Food Chem .2012; 135(4): 2163-2169.

17. Veraverbeke WS, Larroque OR, Bekes F, Delcour JA. In vitro polymerization of wheat glutenin subunits with inorganic oxidizing agents. I. Comparison of single-step and stepwise oxidations of high molecular weight glutenin subunits. Cereal Chem. 2000; 77: 582-588.

18. Veraverbeke WS, Larroque OR, Bekes F, Delcour JA. In vitro polymerization of wheat glutenin subunits with

Trop J Pharm Res, October 2016; 15(10): 2153 
inorganic oxidizing agents. II. Stepwise oxidation of low molecular weight glutenin subunits and a mixture of high and low molecular weight glutenin subunits. Cereal Chem. 2000;77: 589-594.

19. Verbruggen IM, Veraverbek, WS, Delcour JA. In vitro polymerisation of high and low molecular weight glutenin subunits with molecular oxygen. J. Cereal Sci. 2003; 37: 223-229.

20. Cataldo F. On the action of ozone on proteins. Polym Degrad Stab. 2003; 82: 105-114.

21. Sinha NK, Yamamoto $\mathrm{H}, \mathrm{Ng}$ PK. Effects of flour chlorination on soft wheat gliadins analyzed by reversephase high-performance liquid chromatography, differential scanning calorimetry and fluorescence spectroscopy. Food Chem. 1997; 59(3): 387-393.

22. Myers $C D$. Study of thermodynamics and kinetics of protein stability by thermal analysis. In: VR Harwalkar. CY Ma, eds. Thermal analysis of foods. New York: Elsevier Applied Science, 1990;1.
23. Misra NN, Kaur S, Tiwari BK, Kaur A, Singh N, Cullen $P J$. Atmospheric pressure cold plasma (ACP) treatment of wheat flour. Food Hydrocoll. 2015; 44: 115-112.

24. Safonova ON, Kholodova EA, Golota VI. Ozone usage for adjustment of technological properties of wheat baking flour. In 11th International Congress on Engineering and Food. Athens. Greece. 2011: 1-6.

25. Song $Y$, Zheng Q. Dynamic rheological properties of wheat flour dough and proteins. Trends Food Sci Technol. 2007; 18(3): 132-138.

26. Cornec M, Popineau $Y$, Lefebvre J. Characterisation of gluten subfractions by SE-HPLC and dynamic rheological analysis in shear. J. Cereal Sci. 1994; 19(2): 131-139.

27. Wang JS, Zhao MM, Zhao Q Z. Correlation of glutenin macropolymer with viscoelastic properties during dough mixing. J. Cereal Sci. 2007; 45(2): 128-133. 